Bangladesh J. Plant Taxon. 18(1): 77-79, 2011 (June)

(C) 2011 Bangladesh Association of Plant Taxonomists

\title{
VALIDATION OF FOUR NAMES OF CASTANOPSIS (FAGACEAE) FROM HAINAN, SOUTHERN CHINA
}

\author{
Yin Zhijian ${ }^{1}$, Xiang Chunlei and Peng Hua* \\ Key Laboratory of Biodiversity and Biogeography, Kunming Institute of Botany, \\ Chinese Academy of Sciences, Kunming 650204, Yunnan, PR China \\ Keywords: Castanopsis; China; Fagaceae; Hainan; Nomenclature; Validation.
}

Four names of Castanopsis were not validly published because specimens from two gatherings were indicated as types in the original publications. This is contrary to Art. 37.2, which permits two or more specimens to be indicated provided that they belong to a single gathering (but on or after 1 January 1990 a single herbarium must also be specified: Art. 37.7). The names are here validated with the designation of the holotype.

Castanopsis Spach. consists of about 120 species which are widely distributed in tropical and subtropical Asia (Huang and Zhang, 1988; Mabberley, 2008). In China, 58 species of Castanopsis have been recognized (Huang et al., 1999). Recently, four new species, i.e., Castanopsis hairocarpa G. A. Fu, C. oleifera G. A. Fu, C. qingbeiensis G. A. $\mathrm{Fu}$, C. wuzhishangensis G. A. Fu, from Hainan Island in South China were published (Fu, 2001). However, two specimens, representing flowering and fruiting stage, were simultaneously designated as types for them respectively. Therefore, these names were not validly published according to Art. 37.1 of the International Code of Botanical Nomenclature (ICBN, see McNeill et al., 2006). To enable their formal use, these names are herein validated by a holotype designation.

According to the Article 46.2, G. A. Fu is the author of $C$. hairocarpa, C. oleifera, $C$. qingbeiensis and $C$. wuzhishangensis, that is because, for each name validated here, both the name and the validating description and diagnosis are ascribed to Fu.

Holotype of each species were examined in the herbarium HFB, other specimens from the following herbaria were available to us for comparison: CDBI, IBK, IBSC, KUN and PE. As fruit is a very important character for the taxonomy of the genus Castanopsis, thus collections in fruiting stages were designated as holotype respectively.

*Corresponding author. Present address: Herbarium, Kunming Institute of Botany, Chinese Academy of Sciences, Kunming 650204, Yunnan, PR China. E-mail: hpeng@mail.kib.ac.cn

${ }^{1}$ Graduate School of the Chinese Academy of Sciences, Beijing 100049, China 


\section{Validation of the names}

Castanopsis trichocarpa (In the original publications is hairocarpa, which is a ridiculous compound of the English word "hair" and a Greek word "carpa". It is preferable to use another Greek word in the compound: tricho- means hairy.) G. A. Fu, sp. nov. Validated by a full and direct reference to the Latin diagnosis associated with Castanopsis hairocarpa G. A. Fu, Guihaia 21: 96. 2001.

Holotype: G. A. Fu 7739 (HFB), China, Hainan, Wenchang, Gongpo town, Longfeitou village, 3 Oct 1992. - Paratypes: G. A. Fu 7328, 8169, 8219, 8224, 8250, 8251, 10250 (HFB), China, Hainan, Wenchang, Gongpo town, Longfeitou village; G. A. Fu 8249 (HFB), Hainan, Wenchang, Changsa town, Baocaishan village.

Castanopsis trichocarpa is similar to C. choboensis Hickel \& A. Camus and $C$. indica (Roxburgh ex Lindl.) A. DC., but its cupules only cover about basal 1/2 of nuts. The new species is endemic to Wenchang, under rain forests, associated plants include Symplocos racemosa Roxb., Syzygium odoratum (Lour.) DC., Ochna integerrima (Lour.) Merr., Psychotria rubra (Lour.) Poir. The Chinese name of this species is "mao guo zhui" and known as "ruan ci zhui” for local people.

Castanopsis oleifera G. A. Fu, sp. nov. Validated by a full and direct reference to the Latin diagnosis associated with Castanopsis oleifera G. A. Fu, Guihaia 21: 97-98. 2001. Holotype: G. A. Fu 6683 (HFB), China, Hainan, Wenchang, Changsa town, Baocaishan village, 7 Oct 1989. - Paratypes: G. A. Fu 6681, 8107, 8166, 8167, 8109, 8170 (NHF), China, Hainan, Wenchang, Changsa town, Baocaishan village, 18 Dec 1995; G. A. Fu 6681, 7740, 7742, 7743, 7894, 8237, 8238, 8243, 8244, 10174 (NHF), Hainan, Wenchang, Gongpo town, Longfeitou village.

Castanopsis oleifera is mostly similar to C. hainanensis Merr., but the leaf blade of C. oleifera is oblong to elliptic, secondary veins arcuate, while leaf blade of $C$. hainanensis is obovate, ovate-elliptic or broadly ovate, secondary veins straight. $C$. oleifera is endemic to East Wenchang, Hainan, in mixed forest of Litsea pseudoelongata H. Liu, Syzygium hancei Merr. \& L. M. Perry, Psychotria rubra (Lour.) Poir., with the altitude about $20 \mathrm{~m}$. The Chinese name of the species is "you zhui” and known as "jia niu zhui” for local people.

Castanopsis qiongbeiensis G. A. Fu, sp. nov. Validated by a full and direct reference to the Latin diagnosis associated with Castanopsis qingbeiensis G. A. Fu, Guihaia 21: 9697. 2001.

Holotype: G. A. Fu 10248 (HFB), China, Hainan, Wenchang, Gongpo town, Lonfeitou village, 27 Nov 1999. - Paratypes: G. A. Fu 6682, 6960, 7895, 8108, 8171, 8172, 8173 (HFB), China, Hainan, Wenchang, Changsa town, Baocaishan village; G. A. Fu 7744, 8243, 10175, 10249A (HFB), Hainan, Wenchang, Gongpo town, Lonfeitou village; $J$. Xiao 137877 (HFB), China, Hainan, Wenchang, Changsa town, Baocaishan village. 
Castanopsis qiongbeiensis is most similar to $C$. chinensis Hance, from which it differs by its ovate-lanceolate or ovate-oblong leaf blade, and leaves more hard. The new species is confined to Wenchang, Hainan, growing with Litsea pseudlongata H. Liu, Syzygium tephrodes (Hance) Merr. \& L. M. Perry, C. wenchangensis G. A. Fu \& C. C. Huang, Symplocos racemosa Roxb. The Chinese name of this species is "qiong bei zhui” and known as “da ye ke zhui” for local people in Wenchang.

Castanopsis wuzhishanensis G. A. Fu, sp. nov. Validated by a full and direct reference to the Latin diagnosis associated with Castanopsis wuzhishangensis G. A. Fu, Guihaia 21: 95-96. 2001.

Holotype: G. A. Fu 10256 (HFB), China, Hainan, Wuzhishan, in secondary rain forest, 4 Jan 2000. - Paratypes: G. A. Fu 10116, 10251, 10291 (HFB), China, Hainan, Wuzhishan.

Castanopsis wuzhishanensis is morphologically most similar to C. carlesii (Hemsl.) Hayata var. spinulosa W. C. Cheng \& C. S. Chao and C. echinocarpa Miq. var. seminuda W. C. Cheng \& C. S. Chao. Compared to C. carlesii var. spinulosa, leaves of C. wuzhishangensis are more hard and thick, and can be distinguished from C. echinocarpa var. seminuda by its smaller leaves (c. $5.5-10.5 \times 1.5-2.8 \mathrm{~cm}$ ). C. wuzhishangensis is confined to Wuzhishan, Central Hainan with the altitude from 700 to $850 \mathrm{~m}$, associated plants include Eurya nitida Hieron., Lindera kwantungensis (Liou) C. K. Allen, Reevesia longipetiolata Merr. \& Chun, Cyclobalanopsis blakei (Skan) Schottky and Castanopsis hystrix Miq. The Chinese name of this species is "wu zhi shan zhui" and known as "shan bai zhui” for local people in Wenchang.

\section{Acknowledgements}

This study was supported by Kunming Institute of Botany (KIB-Wu-2001-04).

\section{References}

Fu, A.G. 2001. New species of the genus Castanopsis from Hainan. Guihaia 21: 95-98.

Huang C.J. and Zhang, Y.T. 1988. Castanopsis. In: Cheng, H.Y. and Huang, C.J. (eds), Flora Reipublicae Popularis Sinicae 22: 13-80.

Huang, C.J., Zhang, Y.T. and Bruce, B. 1999. Fagaceae. In: Wu, C.Y. and Raven, P. (eds), Flora of China 4 : 314-400.

Mabberley, D.J. 2008. Mabberley’s plant-book: A portable dictionary of the plants. 3rd edition. Cambridge University Press, Cambridge.

McNeill, J., Barrie, F.R., Burdet, H.M., Demoulin, V., Hawksworth, D.L., Marhold, K., Nicolson, D.H., Prado, J., Silva, P.C., Skog, J.E., Wiersema, J.H. and Turland, N.J. 2006. International Code of Botanical Nomenclature (Vienna Code). Regnum Vegetabile, 146. 